\title{
Uncertainty, Electoral Incentives and Political Myopia*
}

\author{
Short form: Uncertainty, Elections and Political Myopia
}

Alessandra Bonfiglioli Gino Gancia

This draft: October 2012

\begin{abstract}
We study the determinants of political myopia in a rational model of electoral accountability where the key elements are informational frictions and uncertainty. We build a framework where political ability is ex-ante unknown and policy choices are not perfectly observable. On the one hand, elections improve accountability and allow to keep wellperforming incumbents. On the other, politicians invest too little in costly policies with future returns in an attempt to signal high ability and increase their reelection probability. Contrary to the conventional wisdom, uncertainty reduces political myopia and may, under some conditions, increase social welfare. We use the model to study how political rewards can be set so as to maximise social welfare and the desirability of imposing a one-term limit to governments. The predictions of our theory are consistent with a number of stylised facts and with a new empirical observation documented in this paper: aggregate uncertainty, measured by economic volatility, is associated to better fiscal discipline in a panel of 20 OECD countries.
\end{abstract}

JEL Classification: E6, H3

\footnotetext{
*Corresponding author: Gino Gancia, CREI, Universitat Pompeu Fabra and Barcelona GSE, Ramon Trias Fargas 25-27, 08005 Barcelona, Spain. E-mail: ggancia@crei.cat. We thank David Myatt, two anonymous referees, Alberto Alesina, Allan Drazen, Georgy Egorov, Ruben Enikolopov, Nicola Gennaioli, John Moore, Massimo Morelli, Torsten Persson, Giacomo Ponzetto, Marko Terviö, Jaume Ventura, Fabrizio Zilibotti and seminar participants at the NBER Summer Institute PEPF 2010, EDP Jamboree 2010, the CEPR Workshop "Politics, Information and the Macroeconomy", Toulouse School of Economics, Universitat Autonoma de Barcelona, Universidade do Minho, University of Helsinki, IMT, IAE, ENTER Jamboree 2012, RES Meeting 2012, CEPR ESSIM 2012, SED Annual Meeting 2012, EEA Annual Meeting 2012, University of Mannheim and University of Zurich for comments. We also thank Tomaz Cajner for reserach assistance. Earlier versions of this paper were circulated with the title "The Political Cost of Reforms". We acknowledges financial support from the ERC Grant GOPG 240989 and the Fundación Ramón Areces.
} 
Governments of democratic countries are often criticised for taking myopic actions. Examples of a short-term bias in policymaking abound, ranging from the ease with which public debt is accumulated and the difficulty in cutting it down, to widely-raised concerns about underinvestment in long-term policies such as education, environmental conservation and basic research. Measures of political myopia also vary significantly across countries and time, hence the importance of studying what conditions make it more or less likley. Economists and political scientists alike have long been intrigued by the idea that elections, while providing a fundamental mechanism of accountability, may at the same time induce a short-term bias (e.g., Nordhaus, 1975; see Eslava, 2011 for a recent survey). Studying how political institutions cope with these sometimes conflicting goals is therefore one of the major questions in political economy.

In this paper, we investigate the determinants of political myopia in a rational model of electoral accountability where the key elements are informational frictions and uncertainty. Consistently with the conventional wisdom, we find that politicians have too weak incentives to take actions and invest in policies with future returns. Differently from most of the literature, however, we find that various forms of uncertainty can alleviate this short-term bias and sometimes increase social welfare. We then examine the implications of our results for the design of optimal political institutions.

Combining the political setup in Rogoff (1990) with the agency model in Holmström (1999), we study the choice of office-motivated politicians to exert effort and to invest in long-term policies with future benefits. Politicians differ solely in ability and elections serve the purpose of ousting those who perform poorly. This selection ex-post shapes political incentives ex-ante: by exerting more effort and investing less, the incumbent can improve current performance in an attempt to signal high ability and therefore increase his reelection probability. Such an opportunistic short-term bias holds even when citizens are rational and aware of political strategies under two conditions. The first is that ability of politicians is initially unknown, so that it must be inferred on the basis of performance. The second is an informational asymmetry between citizens and the incumbent such that effort and resources invested in long-term policies 
are not directly observed by voters. ${ }^{1}$ Since citizens cannot disentangle the effect of ability from policy choices, there is a signal-jamming motive to inflate current performance at the expenses of the future. Despite this, however, in a rational-expectation equilibrium voters correctly foresee the strategy of the incumbent so that they will not be fooled. As a result, the incumbent will not be able to manipulate his reelction probability. Still, his choice to underinvest is sustained by hidden information out of equilibrium: the fact that he can deviate from his optimal strategy in ways unknown to voters. In other words, the incumbent is trapped in an inefficient equilibrium where he is expected to behave myopically and from which he cannot escape for fear of losing office. $^{2}$

Contrary to many existing works, we find that in our setting uncertainty is likely to make investment in long-term policies more viable. The reason for this result is that the short-run bias depends crucially on the sources of uncertainty affecting the precision of the signal that voters can see. If observable measures of performance are poor signals of ability, for instance because the economy is going through a period of high turbulence, the probability of being reelected becomes less sensitive to the choices of the politician, thereby lowering the temptation to engage in signal jamming. Similarly, the action of the politician matters less for reelection when political ability is very dispersed. Thus, more uncertainty about outcomes or ability reduces unambiguously the level of political myopia. Despite these beneficial effects, the welfare consequences are ambiguous because uncertainty worsens both electoral accountability, thereby inducing the incumbent to put less effort, and in some cases selection of politicians. By comparing these contrasting forces, we find a simple condition for welfare to increase or decrease with various forms of uncertainty.

The high tractability of our model allows us to also address two normative questions. First, we study the effect of political rewards on social welfare. By increasing the value to stay in power, higher rewards exacerbate underinvestment, but also induce the incumbent to exert more

\footnotetext{
${ }^{1}$ Following Holmström (1999) and differently from Rogoff (1990), we assume that ability is initially unknown even to the politician. This implies that we consider a moral-hazard model, which is more tractable than signalling games.

${ }^{2}$ The model is therefore consistent with the view that governments are worried by the electoral cost of longterm policies. As Jean-Claude Juncker once said, "We all know what to do, but we don't know how to get reelected once we have done it." It also shows that this view is fully consistent with the evidence that myopic policies do not seem to be rewarded by voters.
} 
effort. We characterise the socially optimal level of compensation arising from this trade-off and find that politicians should be rewarded more when effort is relatively more important than long-term policies and when uncertainty is high. Second, since political myopia arises because incumbents care about reelection, we ask under what conditions imposing a one-term limit may be welfare improving. A term limit promotes investment, but reduces political accountability and hence effort, and gives up the benefit of selection. We find that it may be welfare improving only when political rents from office are high, and when long-term policies are relatively more important than effort and selection.

We then consider some extensions aimed at studying the sensitivity of the results to various aspects of our model. A crucial assumption is that voters cannot perfectly observe political actions, or that an incumbent can take hidden actions which shift upward current performance at the expenses of future outcomes. This information structure, which is used in several other models (e.g., Rogoff 1990, Alesina and Tabellini, 2007, 2008, Ponzetto and Troiano, 2012), appears plausible whenever it is costly for an individual to monitor precisely a government's behaviour. For instance, policies that are difficult to observe ex-ante may include off-budget expenditures, loans and guarantees, vesting of public pension funds or more broadly the allocation of effort between projects with different time horizons. Interestingly, even if monitoring were possible, there may be little incentive to undertake it, or to trust external sources of information, since the equilibrium choice of policies is anyway anticipated by rational voters. We explore these possibilities by showing that our results still apply when voters can observe, albeit imperfectly, political actions. Under some conditions, this additional information turns out to be irrelevant, while in other instances it may indeed alleviate political myopia. Finally, to better understand the role of the time horizon of payoffs for political incentives, we extend the model by adding another policy choice with contemporaneous costs and benefits. We show that, for this type of short-term policies, electoral incetives can lead to the socially optimal outcome.

Our paper builds on agency models where the role of elections is to select the most competent politician. In this setting, incumbent policymakers have career concerns, i.e., they have implicit incentives to perform well to appear talented to voters. Models of this type have been originally 
developed to study labor-market relationships, where an agent seeks to maximise a principal's perception of his competence (Holmström, 1999, Dewatripont et al., 1999a, 1999b). This approach has been applied to politics by Persson and Tabellini (2000), Alesina and Tabellini (2007, 2008) among others. The distinctive feature of these applications is that instruments to provide incentives in politics are much coarser than those available to firms, as they often limit to a retain-or-fire decision. Incumbent politicians want to maximise the probability of reelection, rather than expected competence, with sometimes different implications. ${ }^{3}$ Our contribution is to extend this analysis by studying the electoral incentives on actions with different time profiles of costs and benefits, how they are affected by various forms of uncertainty, and to explore some normative implications for the design of political institutions.

Consistently with the agency literature, we find that career concers (or signal-jamming incentives) can be beneficial, but also detrimental. As in Holmström (1999), they have a beneficial disciplining effect on short-run actions, such as putting effort or refraining from rent seeking, a result that goes back to Barro (1973). But they may also induce myopia. ${ }^{4}$ In the latter case, career concerns pose a trade-off between selection and efficiency which seems particularly relevant in politics. In a similar vein, Dewan and Myatt (2007, 2010, 2012) study the incentives faced by ministers in a government where they can only be fired or promoted and the implications of this reward scheme for the performance and longevity of the government. They also find a trade-off between performance and selection, and study how feedback effects between performance and longevity may lead to multiple equilibria and rich dynamics, such as honeymoon effects, turning points, and sudden crises of confidence. The effect of political rewards on the quality of politicians has also been studied, among others, by Caselli and Morelli (2004), Besley (2004), Besley and Smart (2007), and Mattozzi and Merlo (2008). Contrary to our model, all

\footnotetext{
${ }^{3}$ Another related strand of the literature studies tournaments, whereby incentives are provided through wage increases associated with promotions. Models of this type have been used to characterise the optimal reward structure in firms and to analyse the effects of uncertainty about ability on effort and human capital investment. See, for example, Meyer (1992), Prendergast (1993), Miklós-Tahl and Ullrich (2012) and Waldman (2012). These papers are focused on dynamic incentives, but not on myopic choices.

${ }^{4}$ Other instances in which career concerns can hurt the principal include when they induce an agent to choose an action not because it is right for society, but because it is popular (pandering, as in Maskin and Tirole, 2004) or because it is what an able agent is expected to do a priori (conformism, as in Prat, 2005). The fact that career concerns may induce myopia has been recognised by Stein (1989), although in a very different application to stock markets.
} 
these papers do not focus explicitly on the role of uncertainty and the time horizon of policies.

Models of political myopia have been proposed to study why budget deficits arise and why they are so difficult to eliminate. A short-term bias may result from the strategic interaction of different policymakers who do not fully internalise future costs and/or manipluate public debt to influence each others (e.g., Alesina and Tabellini, 1990, Persson and Svensson, 1989). In these models, political myopia is a function of political instability, i.e., the probability that a party in power loses office. On the contrary, in our model what matters is not so much the reelection probability, but rather the incentive to manipulate it. Influential models of delayed stabilisations have been built on the idea that uncertainty regarding the distribution of gains and losses may lead to a status quo bias (Fernandez and Rodrik, 1991, Ciccone, 2004) or a war of attrition (Alesina and Drazen, 1991). Differently from our paper, these results are based on conflict of interests and tend to suggest that uncertainty induces myopic policies, rather than alleviating them. We show that agency considerations alone may suggest the opposite result.

Finally, our paper is also related to models of political business cycles, where incumbents want to perform well just before elections so as to appear talented (e.g. see Nordhaus, 1975, Rogoff and Sibert, 1988, Rogoff, 1990, Lohman, 1998, Drazen, 2000, Shi and Svensson, 2006). We move beyond this literature by exploring the broader determinants of political myopia, particularly uncertainty, the trade-offs that electoral incentives may pose and the resulting normative implications. Interestingly, our results may suggest the existence of a novel trade-off between political and business cycles, in that an increase in the variance of economic shocks discourages pre-electoral signal jamming. The focus of our paper, however, is not to study how political incentives vary in election and non-election years.

The rest of the paper is organised as follows. Section 1 discusses the empirical observations motivating our analysis. It reviews the existing evidence on the relationship between elections, fiscal disipline and economic outcomes. It also unveils a new pattern in the data: in a panel of OECD countries, periods of high economic volatility are associated to more fiscal discipline. Section 2 builds an agency model of electoral accountability with informational frictions and uncertainty, where political myopia arises from the desire of incumbents to improve current 
performance in an attempt to be reelected. It then shows that uncertainty, by weakening the impact of signal jamming on reelection probability, alleviates myopia but worsens political accountability. Section 3 examines some normative implications of the model. It provides conditions for uncertainty to be welfare improving, it shows how political rewards can be set so as to maximise social welfare and studies the desirability of imposing a one-term limit. Section 4 explores the robustness of the main results to alternative assumptions on information and on the timing of costs and benefits of alternative policies. Section 5 concludes.

\section{Motivating Evidence}

The vast literature on electoral incentives and short-sighted policies has documented a number of empirical regularities. We summarise here those that seem particularly relevant for our paper and we then present some novel findings. First, while economic performance often affects the probability that politicians stay in power, myopic policies such as loose fiscal discipline do not. Second, pre-electoral budget manipulation is more likely to occur in countries where monitoring is more difficult, while fiscal discipline is more likely to occur during times of crisis. Finally, since the literature has not explored the link between uncertainty and myopic policies, we provide some original evidence suggesting that aggregate uncertainty, measured by economic volatility, is associated to more fiscal discipline in a panel of OECD countries.

\subsection{Elections, Economic Performance and Fiscal Policy}

A first set of questions addressed in the literature is whether economic performance and fiscal policies have an impact on reelection probability. The hypothesis that votes depend on economic outcomes received early support in the works of Fair (1978, 2008), Kiewiet and Rivers (1985) and Alesina and Rosenthal (1995). More recently, Brender and Drazen (2008) show on a sample of 74 countries that high growth during the term in office increases the reelection probability, particularly in less developed countries. Using a sample of 21 OECD countries, Buti et al. (2010) find that high levels and growth rates of GDP have a positive impact on the chances of reelection for incumbent governments. Wolfers (2007) provides evidence from U.S. gubernatorial 
elections that good economic performance increases the likelihood that incumbent parties stay in office. On the contrary, many papers have failed to identify empirically a significant effect of fiscal policies on the chance of reelection. Alesina et al. (1998) and Alesina et al. (2010) study the political consequences of fiscal adjustments in a cross section and a panel of OECD countries and find that fiscal austerity has positive or no political effects. Brender and Drazen (2008) find that loose fiscal policies have a negative effect on the probability of reelection in a panel of 74 countries over the period 1960-2003. Peltzman (1992), Brender (2003), and Drazen and Eslava (2010) examine the effect of fiscal performance on reelection at the state and local level in a single country (the United States, Israel, and Colombia, respectively) and find that voters sometimes punish—rather than reward—loose fiscal policies.

A second set of questions concerns the effects of elections and other variables on fiscal discipline. Several papers have tested whether increases in fiscal deficits and government spending are more likely during election years. While the results are sometimes mixed and vary by country, the empirical literature seems to suggest that political budget cycles take place mainly where voters cannot effectively monitor fiscal policies (see, in particular, Shi and Svensson, 2006). More broadly, several papers have found that more political cohesion is related to more fiscal discipline (e.g., Perotti and Kontopoulos, 2002, and other references in Eslava, 2011). Regarding the adoption of measures aimed at reducing government deficits, the literature on delayed stabilisations suggests that these policies are more likely in periods of crisis, when new governments take office and when governments are "strong" (e.g., Alesina et al., 2006). Although economic conditions are found to matter, there is to our knowledge no evidence on the relationship between fiscal discipline and economic uncertainty. The fact that crisis and volatility are typically correlated raises the question of whether part of the effect of economic downturns on political discipline may work through the higher turmoil that they usually bring about. We now provide some preliminary evidence on this hypothesis. 


\subsection{Economic Volatility and Fiscal Discipline}

We study how aggregate uncertainty, measured by economic volatility, is empirically related to fiscal discipline in a panel of 20 OECD countries observed annually between 1975 and $2000 .^{5}$ Following the previous literature, we proxy fiscal discipline with the annual change in the central government deficit as a ratio of GDP (DEFICIT, from the IMF Government Finance Statistics, 2001). As a measure of macroeconomic volatility, we take the standard deviation of the output gap, i.e., the difference between actual and potential GDP over potential GDP, as computed by the OECD based on estimations of the production functions. This variable is meant to capture unexpected variations in economic performance.

In particular, we estimate:

$$
\Delta D E F I C I T_{i t}=\rho D E F I C I T_{i t-1}+\beta_{1} S D_{i t-1, t-5}+\beta_{2} X_{i t-1}+\epsilon_{i t},
$$

where DEFICIT it is the deficit to GDP ratio in country $i$ and year $t, \Delta$ stands for the annual change between year $t-1$ and $t, S D_{i t-1, t-5}$ is the standard deviation of the output gap over the five-year period between $t-5$ and $t-1, X_{i t-1}$ is a vector of control variables and $\epsilon_{i t}$ is the error term. Following the literature on fiscal stabilisations (e.g., Alesina et al., 2006), we include among the controls indicators of economic activity such as the output gap and the growth rate of real GDP per capita, to account for the cycle, and a dummy for fiscal crises, defined as episodes in which government deficit as a share of GDP is above the 20th percentile (i.e., over 7.5 per cent). Finally, we also control for the following political dummy variables obtained from the 2006 release of the Database of Political Institutions compiled by the World Bank: left-wing governments (left), governments in the first two years of office (younggov) and election years. All regressors are lagged one period to account for the fact that policies may be decided the year before they are enacted, and to avoid simultaneity. A coefficient $\beta_{1}<0$ means that an increase in volatility is associated with a reduction in the deficit, which may indicate

\footnotetext{
${ }^{5}$ These countries are: Australia, Austria, Belgium, Canada, Denmark, Finland, France, Germany, Greece, Ireland, Italy, Japan, Netherlands, Norway, Portugal, Spain, Sweden, Switzerland, United Kingdom, United States.
} 
less myopic policies.

We initially treat the error as a random effect and estimate the coefficients using both crosscountry and time-series variation. The results are reported in Table 1. The first specification suggests that countries with higher volatility and larger deficits tend to implement stronger fiscal adjustments. Since both variables are significant, we keep them in the estimation and add other covariates in the following regressions. First, we control for the output gap and the growth rate of real GDP per capita. The negative coefficient of the output gap, in column 2, suggests that countries above potential have better fiscal discipline, while column 3 confirms that economic crises (negative output growth) may trigger fiscal adjustments. In column 4 , we replace economic performance with the indicator of fiscal crisis and find a significant and negative coefficient, confirming the existing evidence that fiscal adjustments tend to follow fiscal crises. When we consider both economic performance and deficit crises, in columns 5 and 6 , all covariates remain significant. Finally, columns 7 and 8 show that political factors such as the proximity of an election, ideology and the tenure of the government are not significantly correlated with variations in the deficit. The sign, magnitude and significance of the coefficient for economic volatility remain unaltered.

Next, since the R-squared in Table 1 suggest that time-series variation has more explanatory power, we include country fixed effects in the estimation of (1). In this case, however, OLS estimates may suffer from inconsistency due to the presence of the lagged dependent variable on the right-hand side. We address this problem by implementing the Kiviet (1995) correction of the standard errors, which requires us to re-write the estimation equation as:

$$
\operatorname{DEFICIT}_{i t}=\widetilde{\rho} D E F I C I T_{i t-1}+\beta_{1} S D_{i t-1, t-5}+\beta_{2} X_{i t-1}+\eta_{i}+\nu_{i t},
$$

with $\widetilde{\rho}=\rho-1 .^{6}$ In this case, $\widetilde{\rho}<1$ would imply that higher deficit to GDP ratios are followed by larger fiscal adjustments. Table 2 reports the estimated coefficients with robust and consistent standard errors under alternative specifications of equation (2). The estimates

\footnotetext{
${ }^{6}$ Adopting the Blundell and Bond (1998) approach to dynamic panel yields similar estimates. The relatively large time-series and reduced cross-sectional dimensions, however, cause problems of over-fitting, which induced us not to report these results.
} 
for lagged DEFICIT in the first row, significant and smaller than one, confirm the result that countries with larger deficits tend to implement stronger adjustments. The coefficients for the standard deviation of the output gap in the second row, negative and significant, confirm the evidence in Table 1 that an increase in economic volatility is followed by a stronger reduction in deficits. Quantitatively, the effects are substantial: a one per cent increase in SD from its average $(1.85$ per cent) is followed by a 0.35 percentage points reduction in the deficit/GDP ratio. For the average country, this means a shift from a 0.2 percentage points increase to a 0.15 percentage points fall in deficit over GDP. When controlling for the output gap, we do not find a significant estimate for this variable. The positive and significant coefficients for the growth rate of real GDP per capita in columns 3,5 and 7, confirm instead the result that bad economic performance tends to be followed by deficit reductions. The result that fiscal crises are conducive to better fiscal discipline is also confirmed by the negative and significant coefficients of columns 4-8.

Motivated by these observations, we now present a model where electoral outcomes depend on economic shocks rather than opportunistic policies and that can shed light on why volatility may alleviate political myopia.

\section{A Model of Politicians, Elections and Myopia}

We study an agency model of political accountability through elections with two time periods. In the first period, a politician of unknown ability makes decisions about effort and investment in long-term policies with returns in the second period. Between periods, there is an election in which voters choose between the incumbent and a challenger. Elections serve the purpose of ousting bad performing politicians. However, this selection ex-post also affects the incentives the incumbent faces ex-ante. We use this model to study the determinants of political myopia, i.e., the incentive to underinvest in long-term policies in an attempt to manipulate voters' believes about ability, with a particular focus on the role of uncertainty. 


\subsection{Preferences and Technology}

The economy is populated by a unit measure of risk-neutral agents which live for two periods and discount the future at rate $\beta \in(0,1]$. Expected utility of the representative citizen is given by

$$
W=\mathbb{E}\left[y_{t}+\beta y_{t+1}\right]
$$

where $y_{t}$ is a suitable measure of performance (e.g., disposable income per capita, or even broader measures) in period $t$, which in turn depends on the actions of a politician. In the first period, a citizen is drawn at random to conduct economic policy, and for this he receives a reward $\gamma>0$ for each period in office. His expected utility is

$$
U=\mathbb{E}\left[y_{t}+\beta y_{t+1}\right]+\gamma-\frac{a^{2}}{2}+\beta p \gamma,
$$

where $a^{2} / 2$ is the cost of exerting effort $a$ and $p$ is his perceived probability of being reelected in the second period. Thus, the incumbent cares about both social welfare, $W$, and his own private costs and benefits. ${ }^{7}$

Performance in the two periods, $y_{t}$ and $y_{t+1}$, depends on the ability of the politician in office, $\theta_{t}$, his choice of long-term policies, $i$, and effort, $a$, and a random shock $\varepsilon_{t}$ :

$$
\begin{gathered}
y_{t}=\theta_{t}+\kappa a-i+\varepsilon_{t}, \\
y_{t+1}=\theta_{t+1}+f(i)+\varepsilon_{t+1} .
\end{gathered}
$$

Investing in long-term policies, $i$, has a cost in terms of current performance and a future return, where the return function $f(i)$ is assumed to be increasing, concave and three-times differentiable with $f^{\prime}(0)=\infty$ and $f^{\prime}(\infty)=0 .{ }^{8}$ From now on, we refer to $i$ as "investment" or "long-term policies" interchangeably. The social value of effort is parameterised by $\kappa \geq 0$.

\footnotetext{
${ }^{7}$ A quadratic cost of effort is chosen for tractability. Any increasing and convex cost function would yield similar results. Alternatively, the model can be rewritten in terms of rent extraction instead of effort by defining $a=-r$ where $r>0$ are rents and $v(r)$ (with $v^{\prime}(r)>0$ and $v^{\prime \prime}(r)<0$ ) is the private utility from rents.

${ }^{8}$ Alternatively, we could have assumed that the incumbent can a take an hidden actions which shift upward current performance, but with a convex cost in period two.
} 
To focus on the interesting choice variables only, we disregard effort in the second period, although it would be straightforward to include. Ability of the politician in office at time $t, \theta_{t}$, is unknown both to the citizens and to the incumbent, but it is drawn from a known distribution $\theta \sim N\left(\bar{\theta}, \sigma_{\theta}^{2}\right) .{ }^{9}$ Finally, $\varepsilon_{t}$ is an i.i.d. shock drawn from a known distribution $\varepsilon \sim N\left(0, \sigma_{\varepsilon}^{2}\right)$ and uncorrelated to ability $(\mathbb{E}[\theta \varepsilon]=0)$.

The agency game between the citizens and the politician can be summarised as follows. The politician chooses $i$ and $a$ before observing the realisation of $\theta_{t}$ and $\varepsilon_{t}$, so as to maximise his payoff (4). After observing $y_{t}$ only, citizens decide whether to keep the incumbent at $t+1$ or to replace him with a new random draw, so as to maximise (3). There are two important asymmetries between the incumbent and the society at large. First, the politician cares about social welfare, $W$, but also about his probability to stay in office, with a weight equal to $\gamma$ on the latter goal. Second, citizens only observe $y_{t}$ and not the actual actions of the politician, $i$ and $a$. This informational asymmetry can be justified on the ground that monitoring perfectly effort, but also policies with future returns, is likely to be difficult. Moreover, it may be hard to observe the effort the politician puts in implementing different policies. Nonetheless, in Section 4 we consider the more general case in which all political choices can be observed, albeit imperfectly.

\section{$2.2 \quad$ Voters}

We solve the model backward. First, we find the election rule chosen by citizens and then we solve for the investment and effort by the incumbent. Voters face an inference problem: they want to reelect a politician with a high $\theta$, but they only observe a noisy signal, $y_{t}=\theta_{t}+\kappa a-i+\varepsilon_{t}$. Thus, they must form expectations on the ability of the incumbent conditional on $y_{t}$. Citizens know the distributions of $\theta$ and $\varepsilon$, and they can foresee the equilibrium level of investment and effort that the politician will choose, $i^{e}$ and $a^{e}$ respectively (to be solved in the next section). Given this information, as in a standard signal-extraction problem, the posterior belief on the

\footnotetext{
${ }^{9}$ The assumption that ability is initially unknown even to the politician simplifies the model by making all incuments ex-ante identical. This assumption can be relaxed following the analysis in Banks and Sundaram (1998).
} 
incumbent's political ability is:

$$
\widehat{\theta}_{t}=\mathbb{E}\left[\theta_{t} \mid y_{t}\right]=\frac{\sigma_{\varepsilon}^{2}}{\sigma_{\theta}^{2}+\sigma_{\varepsilon}^{2}} \bar{\theta}+\frac{\sigma_{\theta}^{2}}{\sigma_{\theta}^{2}+\sigma_{\varepsilon}^{2}}\left(y_{t}-\kappa a^{e}+i^{e}\right) .
$$

That is, the posterior expectation is a weighted average of the prior, $\bar{\theta}$, and the observed signal, $y_{t}-\kappa a_{t}^{e}+i^{e}$, with weights that depend on the precision of the signal: as the variance of noise increases relative to the variance of ability, the signal becomes less and less informative and the posterior expectation converges to the unconditional mean.

Given (6), it is optimal to reelect the incumbent if the belief of his ability is above average, $\widehat{\theta}_{t} \geq \bar{\theta}$, that is if $y_{t} \geq \bar{y}$, with

$$
\bar{y}=\bar{\theta}+\kappa a^{e}-i^{e} .
$$

Thus, the election rule takes a simple threshold form: voters support the incumbent if current performance exceeds a critical level. To find $i^{e}$ and $a^{e}$, we now turn to the optimisation problem of the politician.

\subsection{Politicians}

The incumbent chooses investment, $i$, and effort, $a$, so as to maximise his expected utility (4), given the voting strategy of citizens and his information set. Hence, given that $\mathbb{E}\left[\theta_{t}\right]=\bar{\theta}$ and $\mathbb{E}[\varepsilon]=0$, his problem is:

$$
\max _{\{i, a\}}\left\{\bar{\theta}-i+\kappa a-\frac{a^{2}}{2}+\gamma+\beta\left[\mathbb{E} \theta_{t+1}+f(i)+p \gamma\right]\right\}
$$

subject to:

$$
\begin{aligned}
p & =\operatorname{Pr}\left(y_{t} \geq \bar{y}\right)=\operatorname{Pr}\left(\theta+\kappa a-i+\varepsilon_{t} \geq \bar{y}\right) \\
& =1-G(\bar{y}+i-\kappa a),
\end{aligned}
$$

where $G(\cdot)$ is the c.d.f. of the realisation $\left(\theta+\varepsilon_{t}\right)$, which is normally distributed with mean $\bar{\theta}$ and variance $\sigma_{\varepsilon}^{2}+\sigma_{\theta}^{2}$, and density $g(\cdot)$. 
Note that $p$ is a decreasing function of investment and an increasing function of effort:

$$
\begin{aligned}
& \frac{\partial p}{\partial i}=-g(\bar{y}+i-\kappa a)<0 \\
& \frac{\partial p}{\partial a}=\kappa g(\bar{y}+i-\kappa a)>0 .
\end{aligned}
$$

That is, a marginal increase in $i$ lowers the observed realisation of $y_{t}$ and thus the probability to meet the threshold for reelection. Similarly, a marginal increase in a raises the observed realisation of $y_{t}$ and thus the expected probability of being reelected. Note also that, by distorting the signal, investment and effort may also affect $\mathbb{E} \theta_{t+1}$. However, it turns out that in the rational-expectation equilibrium the election rule maximises $\mathbb{E} \theta_{t+1}$ given the choice of $i$ and $a$. Therefore, an envelope argument guarantees that $\partial \mathbb{E} \theta_{t+1} / \partial i=\partial \mathbb{E} \theta_{t+1} / \partial a=0$. For this reason and to simplify the notation, we use this equilibrium result to disregard the terms $\partial \mathbb{E} \theta_{t+1} / \partial i$ and $\partial \mathbb{E} \theta_{t+1} / \partial a$ in the first-order conditions.

The choice of $i$ must satisfy the following equation:

$$
\beta f^{\prime}(i)=1-\frac{\partial p}{\partial i} \beta \gamma
$$

The left-hand side of (12) represents the marginal benefit of long-term policies, equal to the discounted marginal product of $i$. The right-hand side is the marginal cost, which has two components. The first one is the social cost of $i$ due to foregone resources today. The second component, instead, is the private cost of long-term policies: by investing more for the future, the policymaker worsens current performance and hence his probability to be reelected. This cost to the politician is proportional to the discounted value of staying in office, $\beta \gamma$.

The first-order condition for effort is instead:

$$
a=\kappa+\frac{\partial p}{\partial a} \beta \gamma
$$

That is, the marginal cost of effort is equalised to the marginal social value, $\kappa$, plus the marginal private benefit due to a higher probability of being reelected. The latter term captures the 
disciplining role of elections.

\subsection{Equilibrium Policies and Political Selection}

In the rational-expectation equilibrium, citizens correctly predict investment and effort so that we can impose $i=i^{e}$ and $a=a^{e}$. Thus, (10) and (11) become:

$$
-\frac{\partial p}{\partial i}=\frac{1}{\kappa} \frac{\partial p}{\partial a}=g(\bar{\theta}) \equiv \bar{g}=\left[2 \pi\left(\sigma_{\theta}^{2}+\sigma_{\varepsilon}^{2}\right)\right]^{-1 / 2},
$$

because $G \sim N\left(\bar{\theta}, \sigma_{\theta}^{2}+\sigma_{\varepsilon}^{2}\right)$. Policies satisfy:

$$
\beta f^{\prime}(i)=1+\beta \bar{g} \gamma
$$

and

$$
a=\kappa(1+\beta \bar{g} \gamma)
$$

What are the equilibrium determinants of long-term investment and effort? The next Proposition answers this question by showing the comparative statics of the choice of $i$ and $a$ to changes in the main parameters: the degree of uncertainty, coming from the random ability draw $(\theta)$ and the noise shock $(\varepsilon)$, and the value of staying in office $(\gamma)$.

Proposition 1 The equilibrium investment in long-term policies is increasing in the variance of both noise $\left(\sigma_{\varepsilon}^{2}\right)$ and ability $\left(\sigma_{\theta}^{2}\right)$, and it is decreasing in the level of political compensation $(\gamma):$

$$
\frac{\partial i}{\partial \sigma_{\varepsilon}^{2}}>0 ; \quad \frac{\partial i}{\partial \sigma_{\theta}^{2}}>0 ; \quad \frac{\partial i}{\partial \gamma}<0
$$

The equilibrium level of effort is decreasing in the variance of both noise $\left(\sigma_{\varepsilon}^{2}\right)$ and ability $\left(\sigma_{\theta}^{2}\right)$, and it is increasing in the level of political compensation $(\gamma)$ :

$$
\frac{\partial a}{\partial \sigma_{\varepsilon}^{2}}<0 ; \quad \frac{\partial a}{\partial \sigma_{\theta}^{2}}<0 ; \quad \frac{\partial a}{\partial \gamma}>0
$$

Proof. See Appendix 
The first notable result is that uncertainty promotes long-term policies by lowering their electoral cost, $\bar{g} \gamma$. To see why, recall that incumbents are reluctant to embark in policies with future payoffs because they are afraid that their immediate cost may be interpreted by voters as a sign of low ability. However, when ability and shocks are highly dispersed, the reelection probability depends more on the realisation of $\theta$ and $\varepsilon$, rather than on the choice of $i$. Formally, from (14), $\bar{g}$ decreases as $\sigma_{\varepsilon}^{2}$ and $\sigma_{\theta}^{2}$ rise:

$$
\frac{\partial \bar{g}}{\partial \sigma_{\varepsilon}^{2}}=\frac{\partial \bar{g}}{\partial \sigma_{\theta}^{2}}=-\frac{\bar{g}}{2\left(\sigma_{\theta}^{2}+\sigma_{\varepsilon}^{2}\right)}
$$

It follows that there is a lower incentive to inflate current performance at the expenses of future performance when $\left(\sigma_{\varepsilon}^{2}+\sigma_{\theta}^{2}\right)$ is high. On the contrary, for a given $\bar{g}$, a high value of being in office, $\gamma$, means that the incumbent cares more about reelection and this increases his private cost of long-term policies. Note also that there is an interesting interaction between these effects in that the impact of uncertainty is strong when the reward at stake is high and the impact of $\gamma$ is strong when uncertainty is low.

The effect of uncertainty on effort is precisely the opposite. By the same reasoning as above, when uncertainty is high the marginal effect of an extra unit of effort on the probability of being reelected is small. For a given $\bar{g}$, instead, a high value of being in office, $\gamma$, increases the perceived value of effort. Thus, more uncertainty $\left(\sigma_{\theta}^{2}\right.$ and $\left.\sigma_{\varepsilon}^{2}\right)$ and a lower stake $(\gamma)$ reduce the disciplining effect of elections and the equilibrium effort. ${ }^{10}$

Imposing $i=i^{e}$ and $a=a^{e}$ into (7) and then using (9), the reelection probability turns out to be

$$
p=\operatorname{Pr}\left(\theta_{t}+\varepsilon_{t} \geq \bar{\theta}\right)=\frac{1}{2}
$$

which is just the unconditional probability that the incumbent be more able than the population average. Thus, in equilibrium the choice of investment does not affect the probability of reelection. Yet, what drives the electoral cost of long-term policies (i.e., $\partial p / \partial i<0$ in (12)) is

\footnotetext{
${ }^{10}$ As noted in Alesina and Tabellini (2007), the result for $\sigma_{\theta}^{2}$ contrasts with standard models of career concerns (e.g., Holmström, 1999) where more ability heterogeneity increases effort because it makes the posterior belief on $\theta$, which the agent seeks to maximise, more sensitive to the signal (see equation 6 ).
} 
hidden information out of equilibrium: the fact that politicians can deviate from their equilibrium strategy in ways unknown to voters. Note also that this effect would disappear if there were no uncertainty about $\theta$.

Finally, we can solve for $\mathbb{E} \theta_{t+1}$, i.e., the ex-ante expected ability of the politician in office in the second period, given the equilibrium behaviour of voters and the incumbent. With probability $(1-p)$, the politician will be a new draw with expected ability $\bar{\theta}$. With probability $p$, it will instead be an incumbent who, by virtue of the voting strategy, is expected to be better than the average. Hence:

$$
\mathbb{E} \theta_{t+1}=(1-p) \bar{\theta}+p \mathbb{E}\left(\theta_{t+1} \mid \widehat{\theta}_{t} \geq \bar{\theta}\right)=\bar{\theta}+\frac{\delta}{2},
$$

where $\delta$ represents the "selection effect", that is, the difference between the ex-ante expected ability of a reelected incumbent and the average. This is equal to the average of the posterior belief truncated from below at $\bar{\theta}$, minus the unconditional mean. ${ }^{11}$ Using standard properties of normal distributions yields:

$$
\delta=\frac{2 \sigma_{\theta}^{2}}{\sqrt{\left(\sigma_{\theta}^{2}+\sigma_{\varepsilon}^{2}\right) 2 \pi}}=2 \sigma_{\theta}^{2} \bar{g} .
$$

Note that reelected politicians tend to be better than the average and more so when ability is highly dispersed (there is no benefit from selection if politicians are all alike) and when noise is low (so that it is less likely to reelect bad but lucky politicians).

\section{Welfare Analysis}

We now explore the implications of the model for social welfare. To start with, we compare the equilibrium derived above with a constrained-efficient benchmark and show that politicians choose a suboptimally low level of investment, which we interpret as political myopia. Then, we examine the impact of uncertainty on welfare and derive conditions for the effect to be positive. We also study the effect of political reward and show how it can be set so as to maximise

\footnotetext{
${ }^{11}$ Note that the distribution of the posterior belief is normal with mean $\bar{\theta}$ and variance $\sigma_{\theta}^{4} /\left(\sigma_{\theta}^{2}+\sigma_{\varepsilon}^{2}\right)$.
} 
the expected utility of citizens. Finally, we use the model to address the role of elections and whether or not it is socially desirable to impose a one-term limit to the politician in office.

Using (3), (5) and (18), expected ex-ante social welfare is:

$$
W=\bar{\theta}-i+\kappa a+\beta\left[\bar{\theta}+\frac{\delta}{2}+f(i)\right] .
$$

where $i$ and $a$ solve (15) and (16), respectively. Note that the utility of the incumbent does not appear in (20) since the politician in power is assumed to be infinitesimal. This simple welfare criterion, adopted in many papers including Alesina and Tabellini (2007, 2008), seems appropriate given that, for our purposes, the government consists of those individuals who are subject to electoral accountability, arguably a small group in the society.

The equilibrium derived in the previous Section is inefficient. A benevolent social planner subject to the information set available to agents would choose $i^{F B}$ so as to equate the social benefit to the social cost:

$$
\beta f^{\prime}\left(i^{F B}\right)=1
$$

Comparing (21) to (15), it is immediate to see that the politician chooses too little investment. This short-term bias arises from the fact that, by deviating from the equilibrium strategy, the incumbent can increase his chance to be reelected. In sum (proof in the text):

Proposition 2 In the above environment, investment in long-term policies, $i$, is below the level that would maximise social welfare.

Note also that $W$ is increasing in $a .{ }^{12}$

\subsection{Uncertainty and Welfare}

In the next proposition, we characterise how uncertainty affects ex-ante expected social welfare (20).

\footnotetext{
${ }^{12}$ We implicitly assume that any participation constraint for the politician is not binding. If instead we assumed that the incumbent had a non-zero weight in the social welfare function, then a bounded level of effort would be socially optimal, since the planner would partly internalise its private cost. The effort choice would still be suboptimally low as long as the incumbent's weight is sufficiently low.
} 
Proposition 3 The effect on social welfare of the variance of noise $\left(\sigma_{\varepsilon}^{2}\right)$ and of ability $\left(\sigma_{\theta}^{2}\right)$ is ambiguous:

$$
\begin{aligned}
& \frac{\partial W}{\partial \sigma_{\varepsilon}^{2}}>0 \Longleftrightarrow-\frac{\bar{g} \gamma^{2}}{f^{\prime \prime}(i)}>\sigma_{\theta}^{2}+\kappa^{2} \gamma \\
& \frac{\partial W}{\partial \sigma_{\theta}^{2}}>0 \Longleftrightarrow \sigma_{\theta}^{2}+2 \sigma_{\varepsilon}^{2}-\frac{\gamma^{2} \bar{g}}{f^{\prime \prime}(i)}>\kappa^{2} \gamma
\end{aligned}
$$

Proof. See Appendix

The variance of noise $\left(\sigma_{\varepsilon}^{2}\right)$ has contrasting effects on welfare. First, Proposition 1 shows that noise promotes investment in long-term policies. Given that these are always suboptimally low, this effect tends to increase social welfare. Second, Proposition 1 also shows that noise reduces effort and this tends to lower social welfare. Third, by making luck relatively more important, a higher noise raises the probability to oust a talented incumbent or to confirm a bad one. Thus, $\sigma_{\varepsilon}^{2}$ reduces the selection premium, $\delta$, and hence social welfare. The first effect dominates the other two, so that noise turns out to be welfare improving, when long-term policies are relatively more important than effort and selection. This is more likely to be the case when underinvestment is severe ( $\bar{g} \gamma$ is high), effort is not very valuable (low $\kappa$ ) and ability is very concentrated (low $\sigma_{\theta}^{2}$ ). Given that $\bar{g} \rightarrow 0$ when $\sigma_{\varepsilon}^{2} \rightarrow \infty$, condition (22) cannot be satisfied when $\sigma_{\varepsilon}^{2}$ is high enough. Thus, welfare declines with noise if noise is sufficiently high.

Without additional restrictions, however, welfare can be a highly non-monotonic function of $\sigma_{\varepsilon}^{2}$. Some examples are reported in Figure 1 for the case $f(i)=i^{\alpha}$ and a small $\kappa$. The thin solid line (horizontal) represents the asymptotic level of welfare as $\sigma_{\varepsilon}^{2} \rightarrow \infty$, i.e., when investment is optimal but there is no benefit from selection. The upper curve displays the relationship between $W$ and $\sigma_{\varepsilon}^{2}$ for a high value of $\sigma_{\theta}^{2}$. When ability is very dispersed, selection is so important that an increase in noise is always welfare reducing, despite its positive effect on $i$. The bottom curve corresponds to the opposite scenario in which heterogeneity in ability is very low, so that selection is not very useful. In this case, welfare increases with uncertainty until $\sigma_{\varepsilon}^{2}$ becomes very 


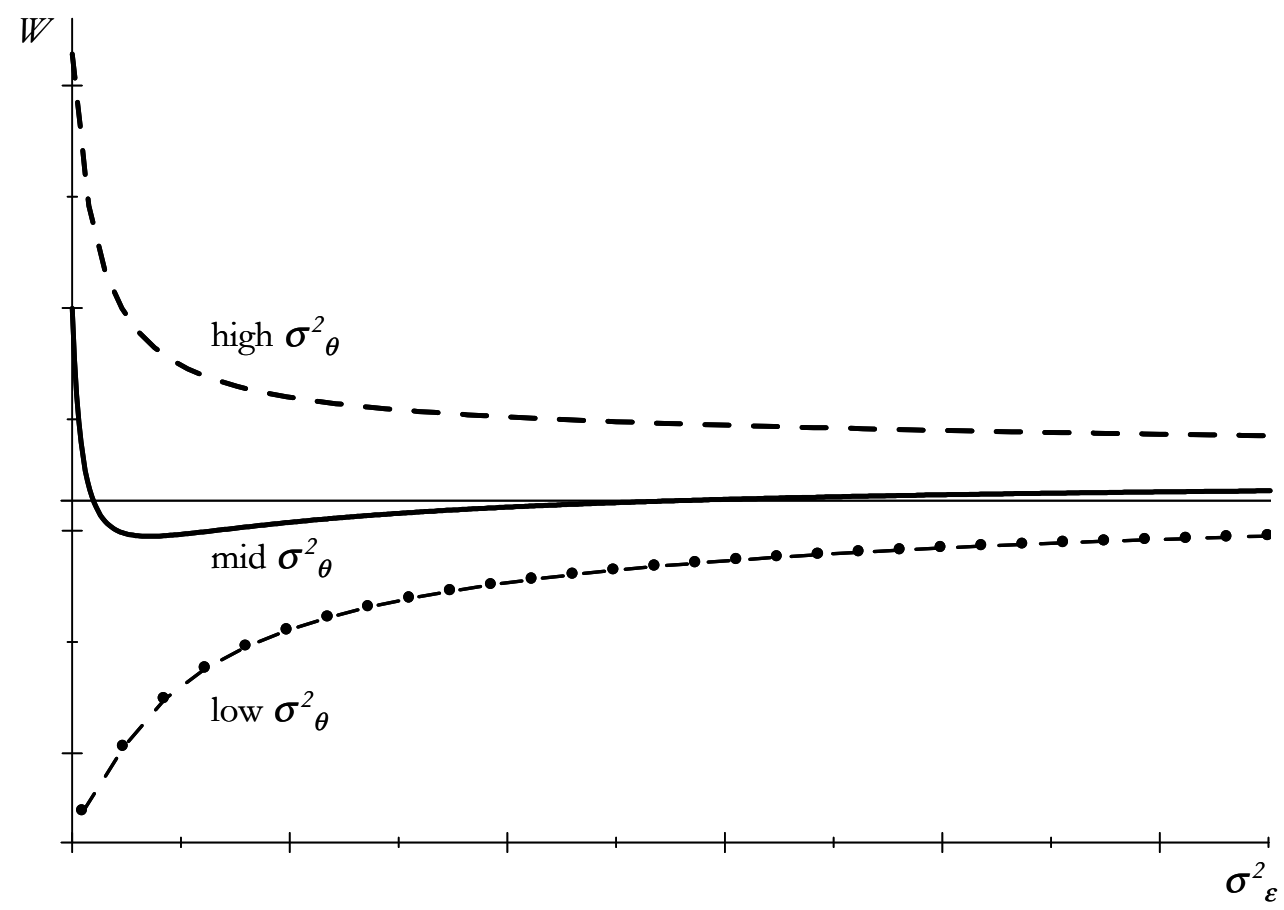

Fig. 1. Uncertainty and Welfare

Note: $W$ is computed assuming $f(i)=i^{\alpha}$ under alternative parameterisations, with high (dashed line), mid (thick solid line) and low (dotted-dashed line) $\sigma_{\theta}^{2}$. The thin solid line is the asymptote for $\sigma_{\varepsilon}^{2} \rightarrow \infty$, i.e. $\delta=0, i=i^{F B}$.

large (the point at which the curve becomes downward sloping is not shown). An intermediate example makes the non-monotonicity more evident.

The variance of ability $\left(\sigma_{\theta}^{2}\right)$ has contrasting welfare effects too. On the one hand, more dispersion in political ability increases $i$ (Proposition 1) and the selection premium, $\delta$ (as can be seen from (19)). These effects tend to increase social welfare. On the other hand, Proposition 1 shows that more heterogeneity reduces effort. The positive welfare effect will dominate when long-term policies and selection are relatively more important than effort. That is, when $\bar{g} \gamma$ is high (so that political myopia is severe), effort is not very valuable (low $\kappa$ ) and ability is dispersed (high $\sigma_{\theta}^{2}$ ). From (23), it is immediate to see that the positive welfare effect of heterogeneity must dominate if $\sigma_{\theta}^{2}$ is sufficiently high.

\subsection{Optimal Political Reward}

What are the welfare effects of political rewards, $\gamma$ ? If rents from office increase, the politician will care more about reelection and this will induce him to exert more effort, but also to 
invest less (see Proposition 1). ${ }^{13}$ The resulting trade-off suggests that there might exist a socially optimal level of political rewards. This possibility is worth exploring because, although $\gamma$ includes psychological rents and private benefits that may be difficult to control, the pay to politicians in power can partly be chosen by the society and varies considerably across countries. ${ }^{14}$ Thus, we now turn to the analysis of the optimum $\gamma$ and its determinant. To rule out unrealistic possibilities, we assume that there is an upper bound to effort, $a \leq a^{\text {max }}$, since time and attention are subject to physiological limitations.

Differentiating expected social welfare, (20), with respect to $\gamma$ yields:

$$
\frac{\partial W}{\partial \gamma}=\kappa \frac{\partial a}{\partial \gamma}+\left[\beta f^{\prime}(i)-1\right] \frac{\partial i}{\partial \gamma}
$$

The first term is the marginal value of political rewards, $M B(\gamma)$ : as long as $\gamma<\gamma^{\max } \equiv$ $\left(a^{\max } / \kappa-1\right) / \bar{g} \beta$, one additional unit increases effort by $\partial a / \partial \gamma$, with a value proportional to $\kappa$. The second term is instead the marginal cost, $M C(\gamma)$ : an extra unit of $\gamma$ induces myopia $(\partial i / \partial \gamma<0)$ and the cost of this is proportional to the severity of underinvestment in equilibrium, $\left[\beta f^{\prime}(i)-1\right]>0$. Using (15) and (16) and simplifying terms, the first-order condition for an interior optimum is:

$$
M B(\gamma)=\kappa^{2}=-\frac{\partial i}{\partial \gamma} \gamma=M C(\gamma)
$$

While $M B(\gamma)$ is constant, the slope of $M C(\gamma)$ is formally analysed in Lemma 1.

Lemma 1 The marginal cost of $\gamma$ is increasing if and only if

$$
f^{\prime \prime}(i)^{2}>f^{\prime \prime \prime}(i) \bar{g} \gamma
$$

Proof. See Appendix

The condition in Lemma 1 is satisfied either if $f^{\prime \prime \prime}(i)<0$ or when $\gamma$ is sufficiently low. In

\footnotetext{
${ }^{13}$ Some evidence that the wage paid to politicians affects their performance is provided, by Besley (2004) for the U.S., Ferraz and Finan (2009) for Brazil, and Gagliarducci and Nannicini (2009) for Italy.

${ }^{14}$ For example, Besley (2004) reports that the US president is paid around $\$ 400,000$, the British prime minister $\$ 270,000$, while the French president $\$ 70,000$. See Diermeier et al. (2005) for a pioneering attempt at quantifying and decomposing the returns to a career in the US Congress.
} 
what follows, we restrict attention to the most interesting case in which this condition is satisfied and $M B$ and $M C$ intersect over the relevant range $\gamma \in\left[0, \gamma^{\max }\right]$. Under this restriction, the solution, $\gamma^{*}$, to $(24)$ is unique and interior. We study the comparative statics of $\gamma^{*}$ to changes in parameters in the following proposition.

Proposition 4 The socially optimal political reward,

$$
\gamma^{*}=\frac{-\kappa^{2} f^{\prime \prime}(i)}{\bar{g}}
$$

is increasing in the variance of both noise $\left(\sigma_{\varepsilon}^{2}\right)$ and ability $\left(\sigma_{\theta}^{2}\right)$, and in the value of effort $(\kappa)$ :

$$
\frac{\partial \gamma^{*}}{\partial \sigma_{\varepsilon}^{2}}>0 ; \quad \frac{\partial \gamma^{*}}{\partial \sigma_{\theta}^{2}}>0 ; \quad \frac{\partial \gamma^{*}}{\partial \kappa}>0
$$

\section{Proof. See Appendix}

An increase in uncertainty (due to either ability dispersion or noise) affects the marginal cost of political compensation while leaving its marginal benefit unaffected. Higher uncertainty means that chance plays a bigger role in reelection, implying that $i$ becomes less reactive to $\gamma$. From (24) we see that this reduces the marginal cost of $\gamma$. As a result, optimal political compensation increases. A higher value of effort, $\kappa$, raises the marginal benefit of $\gamma$ while leaving the marginal cost unaffected. Therefore, the optimal compensation increases when effort is more important.

\subsection{Term Limit}

A fundamental reason why political myopia arises is that incumbents care not only about social welfare, but also their reelection. Thus, a way to align the long-run incentives of politicians and those of the society would be to rule out the possibility of reelection by imposing a one-period term limit. This would set both $p$ and $\partial p / \partial i$ to zero and restore the first-best level of investment. Yet, without electoral incentives, incumbents put less effort. Moreover, by excluding reelection, 
citizens forego the opportunity of retaining well performing candidates. ${ }^{15}$ Therefore, despite its negative effect on long-term policies, the prospect of reelection may be in the interest of the society.

To see why, notice first that allowing for reelection is necessarily better than ruling it out when $\gamma \leq \gamma^{*}$. The reason is that with $\gamma=0$ elections yield the same $i=i^{F B}$ and $a=\kappa$ as the term limit, but with a positive selection premium, $\delta$. Moreover, welfare incrases in $\gamma$ up to $\gamma^{*}$. However, when private rents from office are high and beyond the control of the society (e.g., when corruption is too high) imposing a constitutional one-term limit might be optimal. We now explore this possibility formally.

A one-period term limit, implying $\left\{i=i^{F B}, a=\kappa, \delta=0\right\}$, is socially optimal if it grants an ex-ante expected social welfare, $W^{T L}$, higher than $W$, i.e., when:

$$
W^{T L}-W=\left\{\left[\beta f\left(i^{F B}\right)-i^{F B}\right]-[\beta f(i)-i]\right\}-\beta\left(\frac{\delta}{2}+\kappa^{2} \bar{g} \gamma\right)>0 .
$$

The first term in curly brackets, which is always positive, is the gain due to the higher investment. The second term, instead, is the loss in social welfare for giving up selection and lowering effort. Rearranging and using (19) yields that the term limit is socially optimal if and only if:

$$
\left[\beta f\left(i^{F B}\right)-i^{F B}\right]-[\beta f(i)-i]>\beta \bar{g}\left(\sigma_{\theta}^{2}+\kappa^{2} \gamma\right)
$$

This condition is more likely to hold when selection is not very useful or effective, effort has low value and long-term policies are highly needed.

More formally an increase in $\kappa$ raises the righ-hand side of (25) thereby making the optimality of a term-limit less likely. When $\gamma>\gamma^{*}$, as shown above, $W$ falls with $\gamma$. Hence, the term limit is more desirable when political rents are higher. The effect of uncertainty is instead more complex.

First, note that $\sigma_{\theta}^{2}$ and $\sigma_{\varepsilon}^{2}$ do not affect $W^{T L}$, but have ambiguous effects on $W$, as discussed in Proposition 3. More uncertainty lowers the left-hand side of (25), because it reduces political

\footnotetext{
${ }^{15}$ See Besley and Case (1995) for evidence that term limits do appear to affect policy choices. Yet, from their results it is difficult to sort out the effects on effort and on long-term policies.
} 


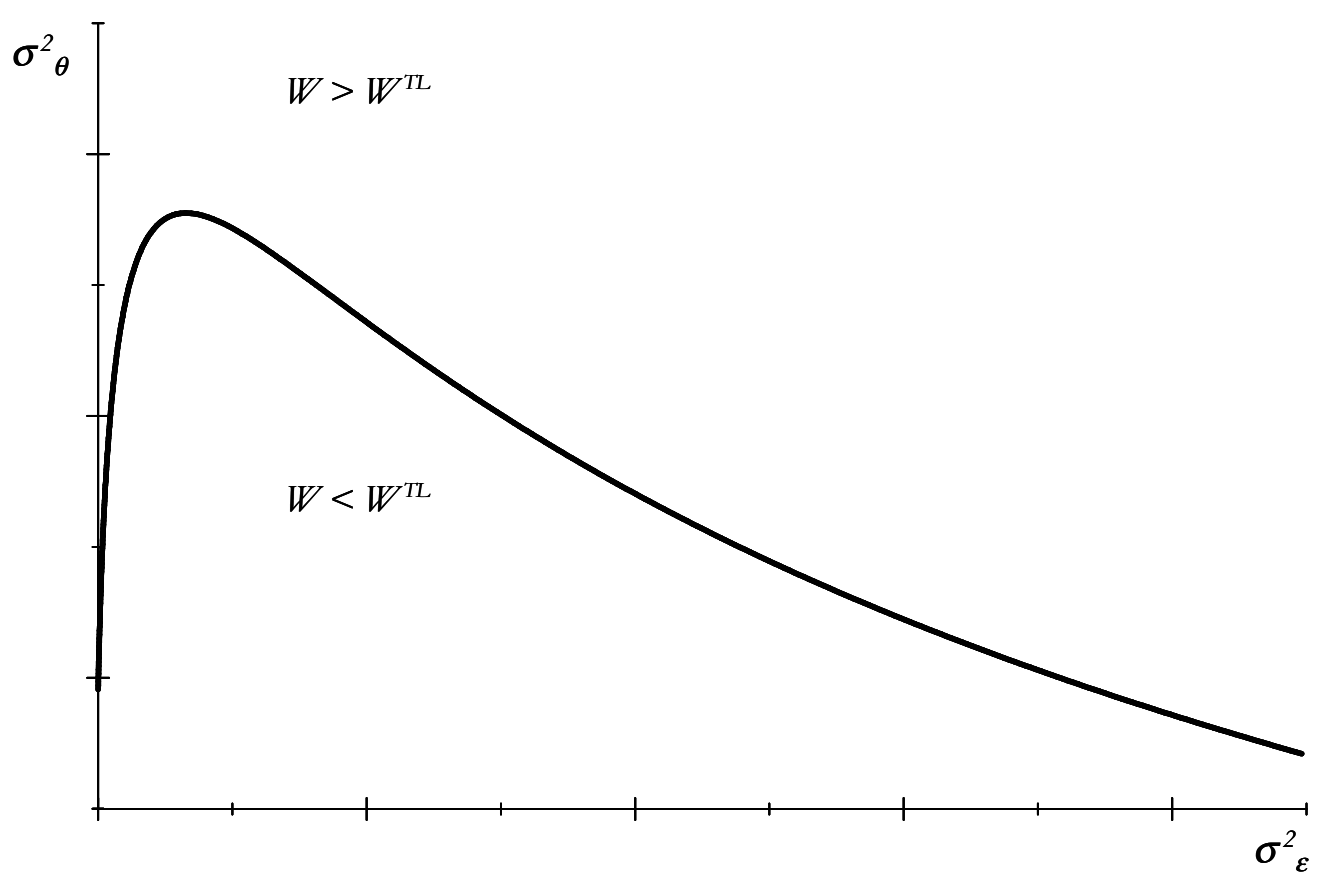

Fig. 2. Uncertainty and Term Limit

Note: $W$ is computed assuming $f(i)=i^{\alpha}$. The thick solid line plots the $\left(\sigma_{\varepsilon}^{2}, \sigma_{\theta}^{2}\right)$ pairs such that $W=W^{T L}$.

myopia (recall, $i$ converges monotonically to $i^{F B}$ as either $\sigma_{\theta}^{2} \rightarrow \infty$ or $\sigma_{\varepsilon}^{2} \rightarrow \infty$ ). This tends to make a term limit less attractive. Yet, the effect on the right-hand side of (25) may depend on the source of uncertainty. When there is more political heterogeneity (higher $\sigma_{\theta}^{2}$ ) there is more to gain from ex-post selection, but there is also less effort in an equilibrium with reelections. The first effect dominates, so that the right-hand side of (25) increases if:

$$
\frac{\partial\left[\bar{g}\left(\sigma_{\theta}^{2}+\kappa^{2} \gamma\right)\right]}{\partial \sigma_{\theta}^{2}}>0 \Longleftrightarrow \sigma_{\theta}^{2}+2 \sigma_{\varepsilon}^{2}>\kappa^{2} \gamma
$$

Thus, if $\sigma_{\theta}^{2}$ is sufficiently high, a term limit is never optimal.

An increase in $\sigma_{\varepsilon}^{2}$, instead, worsens selection and lowers the right-hand side of (25). Since it also lowers the left-hand side, it is unclear whether or not it makes a term limit more attractive. Despite this ambiguity, it can be shown that, if $\sigma_{\varepsilon}^{2}$ is high enough, imposing the term limit cannot be optimal. The reason is that, as $\sigma_{\varepsilon}^{2} \rightarrow \infty, W$ converges to $W^{T L}$ and $\partial W / \partial \sigma_{\varepsilon}^{2}<0$ (the latter follows from Proposition 3), implying that $W$ must converge from above. Thus, we must have $W>W^{T L}$ when noise is sufficiently high. We summarise this discussion in the following 
Proposition (proof in the text):

Proposition 5 There exists a threshold level of heterogeneity in political ability, $\widehat{\sigma}_{\theta}^{2}$, such that for $\sigma_{\theta}^{2}>\widehat{\sigma}_{\theta}^{2}$ holding elections (no term limit) is socially optimal. There exists a threshold level of economic volatility, $\widehat{\sigma}_{\varepsilon}^{2}$, such that for $\sigma_{\varepsilon}^{2}>\widehat{\sigma}_{\varepsilon}^{2}$ holding elections is socially optimal.

More generally, the desirability of a term limit is depicted in Figure 2 in the space $\left(\sigma_{\varepsilon}^{2}, \sigma_{\theta}^{2}\right)$. In the region below the solid line, welfare is higher when a term limit is in place. Clearly, if $\sigma_{\theta}^{2}$ is high enough so that selection is sufficiently important, a term limit is never optimal. Similarly, if $\sigma_{\varepsilon}^{2}$ is high enough, imposing the term limit cannot be optimal either. Moreover, as the figure shows, depending on parameters, a term limit may be more likely to be optimal for intermediate values of noise. This happens because, for low $\sigma_{\varepsilon}^{2}$ selection is very effective and effort is high, which compensate for political myopia.

\section{Robustness and Extensions}

We now study the robustness of the main results derived in Section 2 to alternative assumptions. First, we show that our results can be generalised to a setting where political action is observed, albeit imperfectly. Next, we study the case in which the incumbent politician can choose, in addition to effort and public investment, also short-term policies whose costs and benefits are contemporaneous. We show that the reelection motive does not distort these policies and that all the previous positive and normative results still apply.

\subsection{Imperfect Observability of Policies}

The assumption that voters cannot observe $i$ and $a$ at all is certainly strong. Yet, the main results derived so far hold, at least qualitatively, under much weaker conditions. Assume first that voters can observe independent signals of $i$ and $a$, equal to the actual policy choices plus an additive i.i.d. Normal disturbance. In this case, one may expect that voters would use this additional information to form expectations on the ability of the incumbent, thereby making reelection less subject to manipulation. However, at the time of elections voters can do better: 
since they know the model, and hence also the strategy of the incumbent, they are able to predict the equilibrium choice of policies with no error. On the contrary, using the signals of $i$ and $a$ to form expectations would only add noise to their inference. As a result, voters will rationally decide to ignore the additional signals and attribute any difference between them and their rational expectation to the error term. ${ }^{16}$ This illustrates an important point. Not only does an individual agent have little incentive to gather information to decide his own vote whose weight is infinitesimal, but there is also little incentive to undertake any monitoring activity and/or to trust other sources of information (unless perfectly reliable), because the equilibrium choice of policies can be perfectly anticipated. ${ }^{17}$

Alternatively, we may assume that voters can observe $i$ and $a$ with some probability. In particular, let $\nu$ be the probability that the majority of voters (i.e., the median voter) have no information on political actions. ${ }^{18}$ This new assumption affects the reelection rule. If voters are uninformed, they will reappoint the incumbent if $y_{t}>\bar{y}$, exactly as before. Informed voters, however, observe the sum of competence and the noise shock, $\theta+\varepsilon_{t}$, and will keep the politician in office if this is higher than $\bar{\theta}$. Then, the perceived probability of reelection becomes:

$$
p=\nu \operatorname{Pr}\left(y_{t} \geq \bar{y}\right)+(1-\nu) \operatorname{Pr}\left(\theta+\varepsilon_{t} \geq \bar{\theta}\right) .
$$

Substituting (5) and (7) and rearranging we obtain:

$$
p=\frac{1+\nu}{2}-\nu G(\bar{y}+i-\kappa a)
$$

Comparing (26) to (9), it is immediate to see that the marginal effect of changes in $i$ and $a$ on the chance of reelection is now weighted by the probability that the median voter is uninformed, $\nu$. This is intuitive, since informed voters cannot be fooled, even out of equilibrium. As a result,

\footnotetext{
${ }^{16}$ This is always possible because the noise shocks have infinite support. See also Grossman and Helpman (2001) for similar results.

${ }^{17}$ Of course, if voters could commit ex-ante to pay attention to the signals of $a$ and $i$, this would affect the incentive of the incumbent. However, such a promise would not be credible since there is no form of committing to any predefined voting rule in democratic electoral systems.

${ }^{18}$ Alternatively, with minor modifications to the voting model, $\nu$ can be interpreted as the fraction of uninformed voters. See, for example, Shi and Svensson (2006), Ponzetto (2011) and Ponzetto and Troiano (2012).
} 
the incentive to engage in signal jamming is weaker the lower is $\nu$. The main results of the model, and particularly equations (15) and (16), still hold after multiplying $\bar{g}$ by $\nu$ and the myopic bias is present as long as $\nu>0$. On the other hand, by reducing the reward to effort, a higher $\nu$ will weaken the disciplinig role of elections. In conlclusion, the effect of having more accurate information on political incentives may crucially depend on the type of information (i.e., lower $\sigma_{\varepsilon}^{2}$ versus higher $\left.\nu\right)$.

\subsection{Short-Term vs Long-Term Policies}

To better understand the effect of electoral incentives on policies with different time-horizons, we now add a new government action that mirrors $i$ but with the sole difference of producing immediate payoffs. More precisely, assume that the policymaker can trasform $b$ units of resources at time $t$ into $h(b)$ units of $y_{t}$ :

$$
y_{t}=\theta_{t}+\kappa a+h(b)-b-i+\varepsilon_{t}
$$

with $h^{\prime}(b)>0, h^{\prime \prime}(b)<0$ and $\lim _{b \rightarrow 0} h^{\prime}=\infty$. Note that this policy is different from effort, mostly because the cost of effort was assumed to be private (it does not appear in $y_{t}$ ). We still maintain that voters only observe $y_{t}$, so that the only asymmetry between $i$ and $b$ is when the returns materialise. Clearly, the socially optimal level of $b$ should satisfy the condition $h^{\prime}\left(b^{F B}\right)=1$. Will electoral incentives distort the choice of such a short-term policy?

To answer this question, consider the problem of an incumbent who sets $b$ so as to solve:

$$
\max _{\{i, a, b\}} \mathbb{E}\left[y_{t}+\beta y_{t+1}\right]+\gamma-\frac{a^{2}}{2}+\beta p \gamma
$$

where $y_{t}$ is given by (27) and subject to:

$$
p=\operatorname{Pr}\left(y_{t} \geq \bar{y}\right)=1-G(\bar{y}+i+b-h(b)-\kappa a),
$$

where now $\bar{y}=\bar{\theta}+\kappa a^{e}-i^{e}-b^{e}+h\left(b^{e}\right)$. As before, we are interested in studying electoral 
incentives during the first period and hence disregard the choice of $b$ at $t+1$. The first-order condition for $b$ is

$$
h^{\prime}(b)=1-\beta \gamma \frac{\partial p}{\partial b},
$$

which shows that the government chooses $b$ taking into account both social costs and benefits, but also the effects on the reelection probability $(\partial p / \partial b)$. Yet, differentiating (28) with respect to $b$,

$$
\frac{\partial p}{\partial b}=-g(\cdot)\left(1-h^{\prime}(b)\right),
$$

and substituting this into $(29)$, yields $h^{\prime}(b)=1$. That is, despite the presence of signal-jamming incentives, the government sets the socially optimal level $b^{F B}$. This result comes from the fact that $b^{F B}$ maximises both $y_{t}$ and $p$. In other words, when choosing policies with immediate payoffs, there is no conflict between social welfare and private electoral incentives. Given that short-term policies are always set optimally, the normative results derived in Section 3 still hold.

\section{Conclusions}

In this paper, we have studied the determinants of political myopia and its normative implications in a rational model of electoral accountability where the key elements are informational frictions and uncertainty. In our setting, political myopia arises from the desire of incumbents to improve current performance at the expenses of future outcomes in an attempt to increase their probability of reelection. The main contributions can be summarised as follows. First, we have shown how uncertainty is likely to alleviate myopia, but may also worsen political selection and accountability. Second, by comparing these effects, we have provided conditions for welfare to increase or decrease with the degree and type of uncertainty. Third, we have used the model to study how an optimal political reward should trade off the benefit of higher effort with the cost of more myopic incentives. Fourth, we have shown that, despite the short-term bias, holding elections is better than imposing a one-term limit unless rents form office are very large and heterogeneity in ability is low.

We conclude by mentioning some limitations of our model and possible extensions. Our 
framework can be generalised to show how the correlation between long-term policies and reelection may depend on the information set of agents. If the social cost of long-term policies is random and it is observed only by the incumbent, then a politician facing a lower than average cost may be able to invest more and increase current performance at the same time. In this way, the model could produce a negative correlation between myopic policies and reelection, as often found in the empirical literature on fiscal adjustments (e.g., Alesina et al. 1998 and Brender and Drazen, 2008).

Although our results have been derived in a two-period model, we expect them to hold in an infinite-horizon setup. A simple way to show this would be by assuming that the agency game between voters and politicians is repeated and that incumbents have a two-term limit. Since a reelected incumbent and a new politician would face different incentives, the extended model could then be used to study the dynamics of learning and the so-called incumbency advantage, as in Ashworth (2005) and Ashworth and Bueno de Mesquita (2008). ${ }^{19}$ Alternatively, one could consider a richer time structure and assume that ability follows a first-order moving average process, as in Rogoff (1990).

Another limitation of our approach is that it takes uncertainty as exogenous. In many instances, for example when uncertainty arises from global economic shocks or from a lack of transparency rooted in institutions or cultural traits, this is a reasonable approximation. Yet, some political actions may be aimed precisely at lowering uncertainty, either by means of economic stabilisation or through improved monitoring and accountability procedures. Allowing policy makers to affect the degree of uncertainty they are exposed to would add feedback effects and seems an interesting direction for future research.

The model could also be extended to include the redistributional implications of policies. For instance, if politicians could target certain groups to bear the cost of their actions, then the model might imply timid policies whose costs are efficiently shared when uncertainty is low and bold decisions that are disproportionately costly for political losers when uncertainty is high.

Finally, although we have discussed the empirical support for our theory, including new

\footnotetext{
${ }^{19}$ See also Meyer (1992) for related results in models of promotion tournaments. Conversely, Höffler and Sliwka (2003) show that turnover may be desirable to reset reputational incentives.
} 
evidence on the correlation between economic uncertainty and fiscal discipline, a formal test of the model's predictions goes beyond the scope of this paper. Some implications that could easily be taken to the data are that technocrats or governments close to a term limit should be less myopic, and that more long-term policies should be adopted at the beginning of legislatures. ${ }^{20}$ Moreover, our theory may also predict less political myopia when reelection campaign is more focused on social issues or foreign policy rather than performance, or when the electorate is more polarised along ideological lines, so that it may be harder to swing votes through hidden actions. To conclude, we hope that our paper will stimulate new empirical investigations on the underexplored links between uncertainty and myopic electoral incentives.

Alessandra Bonfiglioli, Institute for Economic Analysis (CSIC), Barcelona GSE and CEPR Gino Gancia, CREI, UPF, Barcelona GSE and CEPR

Submitted on the 26th of February 2012

\footnotetext{
${ }^{20}$ Interestingly, Alesina et al. (2006) provide evidence that young governments are more inclined to fiscal discipline. List and Sturm (2006) provide evidence that U.S. governors who are closer to their term limit tend to manipulate less secondary policy issues. Moreover, Conconi et al. (2011) show that electoral proximity makes U.S. senators more favourable to protectionism, which may also be a manifestation of a myopic bias.
} 


\section{References}

[1] Alesina, A., Ardagna, S. and Trebbi, F. (2006). 'Who Adjusts and When? On the Political Economy of Reforms,' IMF Staff Papers 53, Mundell-Fleming Lecture, pp. 1-29.

[2] Alesina, A., Carloni, D. and Lecce, G. (2010). 'The Electoral Consequences of Large Fiscal Adjustments,' mimeo, Harvard University.

[3] Alesina, A. and Drazen, A. (1991). 'Why are Stabilizations Delayed?,' American Economic Review, vol. 81, pp. 1170-1188.

[4] Alesina, A., Perotti, R. and Tavares, J. (1998). 'The Political Economy of Fiscal Adjustments,' Brookings Papers on Economic Activity, pp. 197-266.

[5] Alesina, A. and Rosenthal, H. (1995). Partisan Politics, Divided Government and the Economy, Cambridge University Press.

[6] Alesina, A. and Tabellini, G. (2007). 'Bureaucrats or Politicians? Part I: A Single Policy Task,' American Economic Review, vol. 97(1), pp. 169-79.

[7] Alesina, A. and Tabellini, G. (2008). 'Bureaucrats or Politicians? Part II: Multiple Policy Tasks,' Journal of Public Economics, vol. 92, pp. 426-447.

[8] Ashworth, S. (2005). 'Reputational Dynamics and Political Careers,' Journal of Law, Economics and Organizations, vol. 21(2), pp. 441-466

[9] Ashworth, S. and E. Bueno de Mesquita (2008). 'Electoral Selection, Strategic Challenger Entry, and the Incumbency Advantage,' The Journal of Politics, vol. 70(4), pp. 1006-1025.

[10] Banks, J. and Sundaram, R. K. (1998). 'Optimal Retention in Agency Problems,' Journal of Economic Theory, vol. 82, pp. 293-323.

[11] Barro, R. (1973). 'The Control of Politicians: An Economic Model,' Public Choice, vol. 14, pp. 19-42. 
[12] Battaglini, M. and Coate, S. (2008). 'A Dynamic Theory of Public Spending, Taxation, and Debt,' American Economic Review, vol. 98(1), pp. 201-236.

[13] Besley, T. (2004). 'Paying Politicians: Theory and Evidence', Joseph Schumpeter Lecture, Journal of the European Economics Association vol. 2(2-3), pp. 193-215.

[14] Besley, T. and Case, A. (1995). 'Does Electoral Accountability Affect Economic Policy Choices? Evidence from Gubernatorial Term Limits,' Quarterly Journal of Economics, vol. 110 (3), pp. 769-798.

[15] Besley, T. and Smart, M. (2007). 'Fiscal Restraints and Voter Welfare,' Journal of Public Economics, vol. 91, pp. 755-773.

[16] Blundell, R. and Bond, S. (1998). 'Initial Conditions and Moment Restrictions in Dynamic Panel Data Models,' Journal of Econometrics, vol. 87, pp. 115-143.

[17] Brender, A. (2003). 'The Effect of Fiscal Performance on Local Government Election Results in Israel: 1989-1998,' Journal of Public Economics, vol. 87(9-10), pp. 2187-2205.

[18] Brender, A. and Drazen, A. (2008). 'How Do Budget Deficits and Economic Growth Affect Reelection Prospects? Evidence from a Large Panel of Countries,' American Economic Review 98(5), 2203-2220.

[19] Buti, M., Turrini, A., Van den Noord, P. and Biroli, P. (2010). 'Reforms and re-elections in OECD countries,' Economic Policy, vol. 61, pp. 61-116.

[20] Caselli, F. and Morelli, M. (2004). 'Bad Politicians,' Journal of Public Economics, vol. 88, pp. 759-782.

[21] Ciccone, A. (2004). 'Resistance to Reform: Status Quo Bias in the Presence of IndividualSpecific Uncertainty: Comment,' American Economic Review, vol. 94(3), pp. 785-795.

[22] Conconi, P., Facchini, G. and Zanardi, M. (2011). 'Policymakers' Horizon and Trade Reforms,' ECARES mimeo. 
[23] Dewan, T. and Myatt, D. (2007). 'Scandal, Protection, and Recovery in the Cabinet,' American Political Science Review, vol. 101(1), pp. 63-77.

[24] Dewan, T. and Myatt, D. (2010). 'The Declining Talent Pool of Government,' American Journal of Political Science, vol. 54, pp. 267-286.

[25] Dewan, T. and Myatt, D. (2012). 'Dynamic Government Performance: Honeymoons and Crises of Confidence,' American Political Science Review, vol. 106, pp 123-145.

[26] Dewatripont, M., Jewitt, I. and Tirole, J. (1999). 'The Economics of Career Concerns, Part II: Application to Missions and Accountability of Government Agencies,' Review of Economic Studies, vol. 66(1), pp. 199-217.

[27] Diermeier, D., Keane, M. and Merlo, A. (2005). 'A Political Economy Model of Congressional Careers,' American Economic Review, vol. 95, pp. 347-373.

[28] Drazen, A. (2000). 'The Political Business Cycle After 25 Years,' NBER Macroeconomics Annuals, Bernanke, Ben and Kenneth Rogoff (Eds.), MIT Press, Cambridge MA.

[29] Drazen, A., and Eslava, M. (2010). 'Electoral Manipulation via Voter-Friendly Spending: Theory and Evidence,' Journal of Development Economics, vol. 92, pp. 39-52.

[30] Eslava, M. (2011). 'The Political Economy of Fiscal Deficits: A Survey,' Journal of Economic Surveys, Vol. 25 (4), pp. 645-673.

[31] Fair, R. (1978). 'The Effect of Economic Events on Votes for President,' Review of Economics and Statistics, vol. 60, pp. 159-173.

[32] Fair, R. (2008). 'Presidential and Congressional Vote-Share Equations,' American Journal of Political Science, vol. 53 (1), pp. 55-72.

[33] Fernandez, R. and Rodrik, D. (1991). 'Resistance to Reform: Status Quo Bias in the Presence of Individual- Specific Uncertainty,' American Economic Review, vol. 81(5), pp. 1146-1155. 
[34] Ferraz, C. and Finan, F. (2009). 'Motivating Politicians: The Impacts of Monetary Incentives on Quality and Performance,' NBER working paper 14906.

[35] Grossman, G. and Helpman, E. (2001). Special Interest Politics, MIT Press, Cambridge MA and London UK.

[36] Holmström, B. (1999). 'Managerial Incentive Problems: A Dynamic Perspective,' Review of Economic Studies, vol. 66(1), pp. 169-182.

[37] Höffler, F. and Sliwka, D. (2003). 'Do New Brooms Sweep Clean? When and Why Dismissing a Manager Increases the Subordinates' Performance,' European Economic Review, vol. 47 , pp. $877-890$.

[38] Kiewiet, D. R. and Rivers, D. (1985). 'A Retrospective on Retrospective Voting,' in Heinz Eulau and Michael S. Lewis- Beck, eds., Economic Conditions and Electoral Outcomes: The United States and Western Europe, New York: Agathon, 1985, pp. 207-31.

[39] Kiviet, J. (1995). 'On Bias, Inconsistency and Efficiency of Various Estimators in Dynamic Panel Data Models,' Journal of Econometrics, vol. 68, pp. 53-78.

[40] List, J. and Sturm, D. (2006). 'How Elections Matter: Theory and Evidence from Environmental Policy,' Quarterly Journal of Economics, vol. 121(4), pp. 1249-1281.

[41] Lohmann, S. (1998). 'Rationalizing the Political Business Cycle: a Workhorse Model,' Economics and Politics, vol. 10(1), pp. 1-17.

[42] Maskin E. and J. Tirole (2004). 'The Politician and the Judge: Accountability in Government,' American Economic Review, vol. 94 (4), pp. 1034-1054.

[43] Mattozzi, A. and Merlo, A. (2008). 'Political Careers or Career Politicians?,' Journal of Public Economics, vol. 92, pp. 597-608.

[44] Meyer, M. (1992). 'Biased Contests and Moral Hazard: Implications for Carreer Profiles,' Annales D'Économie et de Statistique, vol. 25/26, pp. 165-187. 
[45] Miklós-Thal, J. and Ullrich, H. (2012). 'Belief Precision and Effort Incentives in Promotion Contests,' University of Rochester, mimeo.

[46] Nordhaus, W. (1975). 'The political business cycle,' Review of Economic Studies, vol. 42, pp. 169-190.

[47] Peltzman, S. (1992). 'Voters as Fiscal Conservatives,' Quarterly Journal of Economics, vol. 107(2), pp. 327-61.

[48] Perotti, R. and Kontopoulos, Y. (2002). 'Fragmented fiscal policy,' Journal of Public Economics vol. 86, pp. 191-222.

[49] Persson, T. and Tabellini, G. (2000). Political Economics: Explaining Economics Policy, MIT Press, Cambridge MA.

[50] Ponzetto, G. and Troiano, U. (2011). 'Social Capital, Government Expenditures, and Growth,' Barcelona GSE Working Paper 612..

[51] Ponzetto, G. (2011).'Heterogeneous Information and Trade Policy,' Barcelona GSE Working Paper 596.

[52] Prat, A. (2005). 'The Wrong Kind of Transparency,' American Economic Review, vol. 95(3), pp. 862-877.

[53] Prendergast, C. (1993). 'The Role of Promotion in Inducing Specific Human Capital Acquisition,' Quarterly Journal of Economics, vol. 108, pp. 523-534.

[54] Rogoff, K. (1990). 'Equilibrium Political Budget Cycles,' American Economic Review, vol. 80, pp. $21-36$.

[55] Rogoff, K. and Sibert, A. (1988). 'Elections and Macroeconomic Policy Cycles,' Review of Economic Studies, vol. 55(1), pp. 1-16.

[56] Shi, M and Svensson J. (2006). 'Political budget cycles: Do they differ across countries and why?' Journal of Public Economics, vol. 90 (8-9), pp. 1367-1389. 
[57] Waldman, M. (2012). 'Classic Promotion Tournaments Versus Market-Based Tournaments,' International Journal of Industrial Organization, forthcoming.

[58] Wolfers, J. (2007). 'Are Voters Rational? Evidence from Gubernatorial Elections,' Wharton School, University of Pennsylvania, mimeo.

\section{A Appendix}

\section{A.1 Proof of Proposition 1}

Implicit differentiation of (15) with respect to $\sigma_{\varepsilon}^{2}, \sigma_{\theta}^{2}$ and $\gamma$, and using (17) yields:

$$
\begin{aligned}
\frac{\partial i}{\partial \sigma_{\varepsilon}^{2}} & =\frac{\gamma}{f^{\prime \prime}(i)} \frac{\partial \bar{g}}{\partial \sigma_{\varepsilon}^{2}}=-\frac{\gamma}{f^{\prime \prime}(i)} \frac{\bar{g}}{2\left(\sigma_{\theta}^{2}+\sigma_{\varepsilon}^{2}\right)}>0 \\
\frac{\partial i}{\partial \sigma_{\theta}^{2}} & =\frac{\gamma}{f^{\prime \prime}(i)} \frac{\partial \bar{g}}{\partial \sigma_{\theta}^{2}}=-\frac{\gamma}{f^{\prime \prime}(i)} \frac{\bar{g}}{2\left(\sigma_{\theta}^{2}+\sigma_{\varepsilon}^{2}\right)}>0 \\
\frac{\partial i}{\partial \gamma} & =\frac{\bar{g}}{f^{\prime \prime}(i)}<0,
\end{aligned}
$$

since marginal returns to investment are assumed to be decreasing $\left(f^{\prime \prime}(i)<0\right)$.

Differentiation of (16) with respect to $\sigma_{\varepsilon}^{2}, \sigma_{\theta}^{2}$ and $\gamma$, and using (17) yields:

$$
\begin{aligned}
\frac{\partial a}{\partial \sigma_{\varepsilon}^{2}} & =\frac{\partial a}{\partial \sigma_{\theta}^{2}}=-\frac{\kappa \beta \gamma \bar{g}}{2\left(\sigma_{\theta}^{2}+\sigma_{\varepsilon}^{2}\right)}<0 \\
\frac{\partial a}{\partial \gamma} & =\kappa \bar{g} \beta>0 .
\end{aligned}
$$

\section{A.2 Proof of Proposition 3}

Differentiating social welfare $(20)$ w.r.t. $\sigma_{\varepsilon}^{2}$ yields:

$$
\frac{\partial W}{\partial \sigma_{\varepsilon}^{2}}=\frac{\partial a}{\partial \sigma_{\varepsilon}^{2}} \kappa+\left[\beta f^{\prime}(i)-1\right] \frac{\partial i}{\partial \sigma_{\varepsilon}^{2}}+\frac{\beta}{2} \frac{\partial \delta}{\partial \sigma_{\varepsilon}^{2}}
$$


After replacing the term in the bracket with (15), the derivatives $\partial a / \partial \sigma_{\varepsilon}^{2}$ and $\partial i / \partial \sigma_{\varepsilon}^{2}$ from (33) and $(30)$, and $\partial \delta / \partial \sigma_{\varepsilon}^{2}=-\sigma_{\theta}^{2} \bar{g} /\left(\sigma_{\theta}^{2}+\sigma_{\varepsilon}^{2}\right)$, obtains:

$$
\frac{\partial W}{\partial \sigma_{\varepsilon}^{2}}=\frac{\beta \bar{g}}{2\left(\sigma_{\theta}^{2}+\sigma_{\varepsilon}^{2}\right)}\left[-\frac{\bar{g} \gamma^{2}}{f^{\prime \prime}(i)}-\sigma_{\theta}^{2}-\kappa^{2} \gamma\right]
$$

This is positive if and only if the term in brackets is positive, i.e.,

$$
\frac{\partial W}{\partial \sigma_{\varepsilon}^{2}}>0 \Longleftrightarrow-\frac{\bar{g} \gamma^{2}}{f^{\prime \prime}(i)}>\sigma_{\theta}^{2}+\kappa^{2} \gamma
$$

Differentiating social welfare (20) w.r.t. $\sigma_{\theta}^{2}$ yields:

$$
\frac{\partial W}{\partial \sigma_{\theta}^{2}}=\frac{\partial a}{\partial \sigma_{\theta}^{2}} \kappa+\left[\beta f^{\prime}(i)-1\right] \frac{\partial i}{\partial \sigma_{\theta}^{2}}+\frac{\beta}{2} \frac{\partial \delta}{\partial \sigma_{\theta}^{2}}
$$

After replacing the term in the bracket with (15), the derivatives $\partial a / \partial \sigma_{\theta}^{2}$ and $\partial i / \partial \sigma_{\theta}^{2}$ from (33) and $(31)$, and $\partial \delta / \partial \sigma_{\theta}^{2}=\bar{g}\left[2-\sigma_{\theta}^{2}\left(\sigma_{\theta}^{2}+\sigma_{\varepsilon}^{2}\right)^{-1}\right]$, obtains:

$$
\frac{\partial W}{\partial \sigma_{\theta}^{2}}=\frac{\beta \bar{g}}{2\left(\sigma_{\theta}^{2}+\sigma_{\varepsilon}^{2}\right)}\left[-\kappa^{2} \gamma-\frac{\gamma^{2}}{f^{\prime \prime}(i)} \bar{g}+\sigma_{\theta}^{2}+2 \sigma_{\varepsilon}^{2}\right]
$$

This is positive if and only if the term in brackets is positive, i.e.,

$$
\frac{\partial W}{\partial \sigma_{\theta}^{2}}>0 \Longleftrightarrow \sigma_{\theta}^{2}+2 \sigma_{\varepsilon}^{2}-\frac{\gamma^{2} \bar{g}}{f^{\prime \prime}(i)}>\kappa^{2} \gamma
$$

\section{A.3 Proof of Lemma 1}

Recall:

$$
M C(\gamma)=-\frac{\partial i}{\partial \gamma} \gamma=-\frac{\bar{g}}{f^{\prime \prime}(i)} \gamma
$$

where we have substituted (32). Differentiating $M C(\gamma)$ w.r.t. $\gamma$ yields:

$$
\begin{aligned}
\frac{\partial M C(\gamma)}{\partial \gamma} & =\frac{\bar{g} \gamma}{\left[f^{\prime \prime}(i)\right]^{2}} f^{\prime \prime \prime}(i) \frac{\partial i}{\partial \gamma}-\frac{\bar{g}}{f^{\prime \prime}(i)} \\
& =-\frac{\bar{g}}{f^{\prime \prime}(i)}\left[1-\frac{f^{\prime \prime \prime}(i)}{f^{\prime \prime}(i)^{2}} \bar{g} \gamma\right] .
\end{aligned}
$$


This expression is positive if and only if the term in brackets is positive, i.e.

$$
\frac{\partial M C(\gamma)}{\partial \gamma}>0 \Longleftrightarrow f^{\prime \prime}(i)^{2}>f^{\prime \prime \prime}(i) \bar{g} \gamma
$$

\section{A.4 Proof of Proposition 4}

From:

$$
\gamma^{*}=\frac{-\kappa^{2} f^{\prime \prime}(i)}{\bar{g}}
$$

it is immediate to see that $\gamma^{*}$ is increasing in $\kappa$. To find the effect of uncertainty, note that:

$$
\frac{\partial \gamma^{*}}{\partial \sigma_{\varepsilon}^{2}}=\frac{\partial \gamma^{*}}{\partial \sigma_{\theta}^{2}}=\frac{\partial \gamma^{*}}{\partial \bar{g}} \frac{\partial \bar{g}}{\partial \sigma_{x}^{2}}=-\frac{\partial \gamma^{*}}{\partial \bar{g}} \frac{\bar{g}}{2\left(\sigma_{\theta}^{2}+\sigma_{\varepsilon}^{2}\right)}
$$

for $x=\varepsilon, \theta$. Next, differentiate $\gamma^{*}$ w.r.t. $\bar{g}$ :

$$
\frac{\partial \gamma^{*}}{\partial \bar{g}}=\frac{\kappa^{2} f^{\prime \prime}(i)-\kappa^{2} f^{\prime \prime \prime}(i) \frac{\gamma \bar{g}}{f^{\prime \prime}(i)}}{\bar{g}^{2}}<0
$$

under the condition in Lemma 1 , which is assumed to be satisfied at $\gamma^{*}$. Thus, $\partial \gamma^{*} / \partial \sigma_{\varepsilon}^{2}=$ $\partial \gamma^{*} / \partial \sigma_{\theta}^{2}>0$ 
Table 1

Economic Volatility and Deficit Reduction

20 OECD Countries, 1975-2000, Panel RE

\begin{tabular}{|c|c|c|c|c|c|c|c|c|}
\hline & 1 & 2 & 3 & 4 & 5 & 6 & 7 & 8 \\
\hline DEFICIT & $\begin{array}{l}-0.141 * * * \\
{[0.027]}\end{array}$ & $\begin{array}{l}-0.127 * * * \\
{[0.029]}\end{array}$ & $\begin{array}{l}-0.149 * * * \\
{[0.033]}\end{array}$ & $\begin{array}{l}-0.234 * * * \\
{[0.040]}\end{array}$ & $\begin{array}{l}-0.220^{* * *} \\
{[0.048]}\end{array}$ & $\begin{array}{l}-0.234 * * * \\
{[0.052]}\end{array}$ & $\begin{array}{l}-0.216 \text { *** } \\
{[0.049]}\end{array}$ & $\begin{array}{l}-0.229 * * * \\
{[0.052]}\end{array}$ \\
\hline SD & $\begin{array}{l}-0.191 * \\
{[0.098]}\end{array}$ & $\begin{array}{l}-0.256^{* *} \\
{[0.116]}\end{array}$ & $\begin{array}{l}-0.238^{* *} \\
{[0.095]}\end{array}$ & $\begin{array}{l}-0.201 * * \\
{[0.095]}\end{array}$ & $\begin{array}{l}-0.266^{* *} \\
{[0.111]}\end{array}$ & $\begin{array}{l}-0.247 * * \\
{[0.102]}\end{array}$ & $\begin{array}{l}-0.244 * * \\
{[0.105]}\end{array}$ & $\begin{array}{l}-0.236^{* *} \\
{[0.100]}\end{array}$ \\
\hline OUTPUTGAP & & $\begin{array}{l}-0.095^{* *} \\
{[0.042]}\end{array}$ & & & $\begin{array}{l}-0.094 * * \\
{[0.044]}\end{array}$ & & $\begin{array}{l}-0.089 * * \\
{[0.044]}\end{array}$ & \\
\hline $\operatorname{dlog}(\mathrm{GDP})$ & & & $\begin{array}{l}31.882^{* * *} \\
{[5.530]}\end{array}$ & & & $\begin{array}{l}31.533 \text { *** } \\
{[5.553]}\end{array}$ & & $\begin{array}{l}31.381 \text { *** } \\
{[5.440]}\end{array}$ \\
\hline CRISIS_DEF & & & & $\begin{array}{l}-1.226^{* * *} \\
{[0.457]}\end{array}$ & $\begin{array}{l}-1.217^{* *} \\
{[0.488]}\end{array}$ & $\begin{array}{l}-1.113 * * \\
{[0.535]}\end{array}$ & $\begin{array}{l}-1.158^{* *} \\
{[0.535]}\end{array}$ & $\begin{array}{l}-1.063^{*} \\
{[0.573]}\end{array}$ \\
\hline election & & & & & & & $\begin{array}{l}0.295 \\
{[0.185]}\end{array}$ & $\begin{array}{l}0.157 \\
{[0.189]}\end{array}$ \\
\hline left & & & & & & & $\begin{array}{l}0.267 \\
{[0.259]}\end{array}$ & $\begin{array}{l}0.161 \\
{[0.224]}\end{array}$ \\
\hline younggov & & & & & & & $\begin{array}{l}0.354 \\
{[0.237]}\end{array}$ & $\begin{array}{l}0.369 * \\
{[0.209]}\end{array}$ \\
\hline Observations & 346 & 346 & 346 & 346 & 346 & 346 & 346 & 346 \\
\hline Countries & 20 & 20 & 20 & 20 & 20 & 20 & 20 & 20 \\
\hline Country-FE & $\mathrm{NO}$ & $\mathrm{NO}$ & $\mathrm{NO}$ & $\mathrm{NO}$ & $\mathrm{NO}$ & $\mathrm{NO}$ & $\mathrm{NO}$ & $\mathrm{NO}$ \\
\hline R2 (within) & 0.120 & 0.106 & 0.232 & 0.138 & 0.128 & 0.248 & 0.141 & 0.257 \\
\hline R2 (between) & 0.0492 & 0.0811 & 0.278 & 0.00611 & 0.0151 & 0.172 & 0.00186 & 0.137 \\
\hline
\end{tabular}

Note. Dependent variable is $\triangle$ DEFICIT $=$ annual change in government deficit as a share of GDP. Regressors are lagged values of: DEFICIT; $\mathrm{SD}=$ standard deviation of the output gap over the previous five years; output gap; $\operatorname{dlog}(\mathrm{GDP})=$ growth rate of real GDP per capita; CRISIS_DEF = dummy taking value 1 if DEFICIT is less than or equal to -7.5 ; election $=$ dummy for legislative and/or executive elections; left $=$ dummy for left-wing governments; younggov $=$ dummy for governments in the first two years of office. Regressions are performed with least squares with random effects. Standard errors, in brackets, are clustered by country and robust. ***, ** and * denote significance at 1, 5 and 10 per cent level. 
Table 2

Economic Volatility and Deficit

20 OECD Countries, 1975-2000, Panel FE

\begin{tabular}{|c|c|c|c|c|c|c|c|c|}
\hline & 1 & 2 & 3 & 4 & 5 & 6 & 7 & 8 \\
\hline DEFICIT & $\begin{array}{l}0.843 * * * \\
{[0.0468]}\end{array}$ & $\begin{array}{l}0.852^{* * *} \\
{[0.047]}\end{array}$ & $\begin{array}{l}0.819 * * * \\
{[0.042]}\end{array}$ & $\begin{array}{l}0.725^{* * *} \\
{[0.047]}\end{array}$ & $\begin{array}{l}0.734^{* * *} \\
{[0.048]}\end{array}$ & $\begin{array}{l}0.729 * * * \\
{[0.044]}\end{array}$ & $\begin{array}{l}0.735^{* * *} \\
{[0.047]}\end{array}$ & $\begin{array}{l}0.728 * * * \\
{[0.044]}\end{array}$ \\
\hline SD & $\begin{array}{c}-0.332 * * \\
{[0.148]}\end{array}$ & $\begin{array}{l}-0.344^{* *} \\
{[0.152]}\end{array}$ & $\begin{array}{l}-0.324 * * \\
{[0.136]}\end{array}$ & $\begin{array}{l}-0.351^{* *} \\
{[0.148]}\end{array}$ & $\begin{array}{l}-0.361 * * \\
{[0.151]}\end{array}$ & $\begin{array}{l}-0.349^{* * *} \\
{[0.136]}\end{array}$ & $\begin{array}{l}-0.311^{* *} \\
{[0.155]}\end{array}$ & $\begin{array}{l}-0.337^{* *} \\
{[0.140]}\end{array}$ \\
\hline OUTPUTGAP & & $\begin{array}{c}-0.024 \\
{[0.048]}\end{array}$ & & & $\begin{array}{c}-0.021 \\
{[0.049]}\end{array}$ & & $\begin{array}{r}-0.014 \\
{[0.049]}\end{array}$ & \\
\hline $\mathrm{d} \log (\mathrm{GDP})$ & & & $\begin{array}{l}0.315^{* * *} \\
{[0.044]}\end{array}$ & & & $\begin{array}{l}0.309 * * * \\
{[0.044]}\end{array}$ & & $\begin{array}{l}0.308^{* * *} \\
{[0.044]}\end{array}$ \\
\hline CRISIS_DEF & & & & $\begin{array}{l}-1.317 * * * \\
{[0.434]}\end{array}$ & $\begin{array}{l}-1.311 \text { *** } \\
{[0.446]}\end{array}$ & $\begin{array}{l}-1.022^{* *} \\
{[0.417]}\end{array}$ & $\begin{array}{l}-1.241 * * * \\
{[0.449]}\end{array}$ & $\begin{array}{l}-0.982^{* *} \\
{[0.418]}\end{array}$ \\
\hline election & & & & & & & $\begin{array}{l}0.253 \\
{[0.267]}\end{array}$ & $\begin{array}{l}0.130 \\
{[0.246]}\end{array}$ \\
\hline left & & & & & & & $\begin{array}{l}0.490^{*} \\
{[0.298]}\end{array}$ & $\begin{array}{l}0.184 \\
{[0.279]}\end{array}$ \\
\hline younggov & & & & & & & $\begin{array}{l}0.480^{*} \\
{[0.294]}\end{array}$ & $\begin{array}{l}0.543 * * \\
{[0.275]}\end{array}$ \\
\hline Observations & 346 & 346 & 346 & 346 & 346 & 346 & 346 & 346 \\
\hline Countries & 20 & 20 & 20 & 20 & 20 & 20 & 20 & 20 \\
\hline Country-FE & YES & YES & YES & YES & YES & YES & YES & YES \\
\hline R2 (within) & 0.120 & 0.120 & 0.272 & 0.140 & 0.248 & 0.140 & 0.262 & 0.155 \\
\hline R2 (between) & 0.0508 & 0.0542 & 0.0949 & 0.0141 & 0.180 & 0.0150 & 0.119 & 0.00123 \\
\hline
\end{tabular}

Note. Dependent variable is DEFICIT $=$ government deficit as a share of GDP. Regressors are lagged values of: DEFICIT; $\mathrm{SD}=$ standard deviation of the output gap over the previous five years; output gap; d $\log (\mathrm{GDP})=$ growth rate of real GDP per capita; CRISIS_DEF = dummy taking value 1 if DEFICIT is less than or equal to -7.5 ; election $=$ dummy for legislative and/or executive elections; left $=$ dummy for left-wing governments; younggov $=$ dummy for governments in the first two years of office. Regressions are performed with least squares (LSDV) with country fixed effects. Standard errors, in brackets, are corrected for heteroskedasticity and consistency with Kiviet (1995) procedure. ***, ** and * denote significance at 1,5 and 10 per cent level. 